Tamas Kozak - Radovan Madlenak - Gyorgy Ivan Neszmelyi

\title{
HOW THE LEAN MANAGEMENT DECISION INFLUENCES THE TRANSPORTATION COST IN THE SUPPLY CHAIN?
}

The purchase decisions require information on where each phase in aretail supply chain should be placed. The presented method is an integrated tool for retail supply chain totransaction cost optimization. The model does not only present a company-level lean management's decisions within a supply chain, but it also shows the exact methodto optimize the supply chain competitiveness. The allocation model also illustrates how the purchase decisions are allocated for producer, distributor and retail companies. The complexity of the allocation model may be affected by the size of the logistic costs, the algorithm used to calculate the supply chain purchase decisions and the final needs of the customers. The lean management approach could be a redemption to a company, but the results do not help to enhance competitiveness for the whole supply chain in every case. In this paper, a model method is demonstrated that helps to gain benefit of the lowest cost of integrated inventory management decisions. One of the essential parts ofthis research is that not onlythe lean management' result is considered, but effects of purchase decisions are integrated into the whole retail supply chain, as well. This type ofintegrated approachcan have an exponential impact on profitability on supply chain level effectiveness. In the paper are discussed issues that are important from the perspective of carriers, truck owners and operators, transportation policy makers and shippers. Different capacities of transportation and their costs and performance characteristics from lean aspect are discussed as well.

Keywords: lean management, category management, inventory management, gross margin, supply chain, transportation

\section{Keyconcepts for the research approaches}

Traditional standard approach where the transportation cost optimised itself is in many ways inadequate and has been overcome nowadays. Therefore, a new, progressive approach based on the latest lean knowledge and supply chain technologies need to be sought. This paper describes a progressive method of lean supply chain metrology in more detail, applied to assessing the impact of transportation cost in supply chain.

The methodological research approach is affected mainly by three areas, which are discussed in the paper. The selected and discussed business themes are:

- Supply Chain Management

- Inventory Management

- Transportation Management

- Lean Management.

Other business issues could be identified which influence the research topic, in spite of all these the direct strategic drivers are examined in this paper. In several case these issues are in contract with each other from the effectiveness point of view, in the paper the method is presented to solve the conflicts.

\subsection{Introduction}

Transportation refers to the movement of goods from location 'A' to location 'B' as it makes its way from the beginning of a supply chain to the customer. Transportation is one of the most important supply chain drivers because products are rarely produced and consumed in the same area mainly in retail business [1]. The supply chain strategy explores the issues and provides answers to problem of optimizing operations in any business system, whether it be manufacturing, mortgage loan processing, or supply chain management [2]. In this definition, throughput refers to the rate at which sales to the end customer occur. Depending on the market being served, sales or throughput occur for different reasons. In some markets, customers value and will pay for high levels of service. In other markets customers seek simply the lowest price for an item. There are five areas where companies can make decisions that will define their supply chain capabilities: production, inventory, location, transportation, and information [3].

Traditionally, manufacturers were the dominant forces in the supply chain in the consumer goods industry, but with the trend towards the retail consolidation and

\footnotetext{
Tamas Kozak ${ }^{1}$, Radovan Madlenak ${ }^{2, *}$, Gyorgy Ivan Neszmelyi ${ }^{1}$

${ }^{1}$ Department of Commerce, Faculty of Commerce, Hospitality and Tourism, Budapest Business School, University of Applied Sciences, Hungary

${ }^{2}$ University of Zilina, Slovakia

*E-mail of corresponding author: radovan.madlenak@fpedas.uniza.sk
} 
concentration of large retailers, power in the supply chain has been shifting towards the retail level [4]. Whereas manufacturers previously designed, produced, promoted and distributed their goods, retailers have been able to exert pressure back into the supply chain. Retailers convinced manufacturers to change their supply chain strategies and, for example, include tailored pallet packs, scheduled deliveries, continuous replenishment systems, etc. [5].

The supply chain in the consumer goods industry includes all the parties directly or indirectly involved in receiving and fulfilling customer requests, e.g. manufacturers, suppliers, wholesalers, retailers, third party service providers (transporters, warehouses) and customers [1]. Supply chains are dynamic and involve the constant flow of products, information and finance between the different stages. The first flow (products and related services) is one of the main elements in supply chain management. Traditionally, it is the major topic in logistics, because customers expect their orders to be delivered on time, reliably and damage-free. Information flows comprise, for example, orders, inventory, demand or sales data. These flows are important for replenishment and (demand) forecasting at all the stages of the supply chain. Financial flows include the transfer of funds or cash between the supply chain partners [5].

\subsection{Key concepts of inventory management}

One of the most important merchandise management tasks of the planning process is to develop an optimal purchase plan. An assortment is a set of stock keeping units (SKUs) that a retailer offers in a merchandise category in each of their stores. The variety, or breadth of a retailer's merchandise is the number of different merchandise categories offered, and the assortment, or depth of merchandise is the number of SKUs within each category. In the context of merchandise planning, the concepts of variety and assortment are applied to one merchandise category in the given retail department or store. On the category level, variety reflects the number of different types of merchandise and assortment is number of SKUs per type. The process of determining the variety and assortment within a category is called editing the assortment. When editing the assortment for a given category, the effect of assortments on gross margin return on investment (GMROI), the complementarities and possible substitutes between categories and the effects of assortments on the buying behavior should be considered, as well as the physical characteristics of the store and the shelves [6]. In developing the assortment plan, the retailer needs to seek an increase in sales by offering greater breadth and depth, but at the same time inventory turnover and GMROI will potentially decrease because of the increased inventory investment. Increasing assortment breadth and depth may also decrease gross margin. For example, the more SKUs offered, the greater the chance of breaking sizes- that is, stocking out of a specific size or color of SKU. If stockout occurs of a popular SKU in a fashion merchandise category and the retailer cannot reorder it during the season, they would typically discount the entire merchandise type, thus reducing the gross margin. The retailer's objective is to entirely remove the merchandise type from the assortment, so customers would not be disappointed when they do not find the size and color they want [7]. When the retailer develops an assortment plan, they should consider the degree to which the categories complement each other in the given department. If the retailer maintains a wider assortment of goods, this leads to an increase in the more profitable accessory sales. Retailers typically make modelstock plans for the different product types in a portfolio. For example, they mostly classify their merchandise as A, $\mathrm{B}$, and $\mathrm{C}$ products, based on the sales volume or the gross margin. The basic assortment of a category is stocked in the given shop [8]. A larger shelf means more available space, so more SKUs can be placed on it, which increases the GMROI, but the final goal is to maximize the portfolio level yield. In the next part it is examined how the portfolio level yield can be optimized by changing the size of space that each product category occupies on a shelf - taking their sales and gross margin increasing potency into account [9].

\subsection{Key concepts of the lean management}

Transportation refers to movement of product from one location to another as it makes its way from thebeginning of a supply chain to the customer. Transportation is an important supply chain driver because in retail products are often carried and consumed in the trade location. Transportation is a significant component of the costs incurred by most supply chains.

To understand transportation in a supply chain, it is important to consider the perspectives of all retailer's parties. A carrier makes investment decisions regarding the transportation equipment (locomotives, trucks, airplanes, etc.) and in some cases infrastructure (rail) and then makes operating decisions to try to maximize the return from these assets. A shipper, in contrast, uses transportation to minimize the total cost (transportation, inventory, information-sourcing and facility) while providing an appropriate level of responsiveness to the customer. The effectiveness of carriers is influenced by infrastructure such as ports, roads, waterways and airports and the asset capacity in transportation. Most transportation infrastructure throughout the world is owned and managed mainly by distributor and producer.

The design of a transportation network affects the performance of a supply chain by establishing theinfrastructure within which operational transportation decisions regarding scheduling and routing are made. A well-designed transportation network allows a supply chain to achieve the desired degree of responsiveness at a low cost. Three basic questions need to be considered when designing a transportation network between two stages of a supply chain: 
1. Should transportation be direct or through an intermediate site?

2. Should the intermediate site stock product or only serve as a cross-docking location?

3. Should each delivery route supply a single destination or multiple destinations (milk run)?

Based on the answers to these questions, the supply chain ends up with a variety of transportation networks. In this paper we discuss these options in the context of a seller with partners [1].

\subsection{Key concepts of transportation management}

Mass production is based on producing the large lots of identical items to meet anticipated demand. This makes great efficiencies possible because the costs of setups, tooling, etc. are amortized over a very large number of units, making the per-unit costs very low. That also means inventory (queues for parts and materials), and longer cycle times due to the queue are also crucial to retail businesses [10]. Production is to schedule to demand, product flow focuses on the object of customer value. The product, design, service, order, etc., that is being created for the customer. All the work practices in supply chain are carefully evaluated and rethought to eliminate stoppages of any kind so the object of value proceeds smoothly and continuously to the customer [11].

Tools, such $5 \mathrm{~S}$ is the starting point for lean deployment. $5 \mathrm{~S}$ stands for Sort, Set in order, Shine, Standardize, and Sustain. These terms are defined as follows: Sort-Clearly distinguish what is necessary to do the job from what is not. Eliminate the unnecessary. Set in order-Put needed items in their correct place to allow for easy accessibility and retrieval. Shine-Keep the workplace clean and clear of clutter. This promotes safety as well as efficiency. Standardizedclean-up: develop an approach to maintaining orderly work environment that works. Clean and SustainMake a habitof maintaining your workplace [12].

Constraints, or bottlenecks, require special attention. Aprocess constraint is that step or part of the process that limits the throughput of the entire process considering that the producer does not hold inventory, "suddenly" carry the goods for distributor. When a constraint isn't producing, the stocking capacity needs to be considered Every effort needs to be focused on assuring that the companies have sufficient transportation and stocking resources to keep running. Every unit produced by the constraint is of acceptable quality in order to match with customer needs. The constraint is operated in as efficient a manner as possible [13].

Level loading is the process of generating a schedule that is level, stable, smooth and responsive to the market. The goal of level loading is to make the same quantity of an item every day. It is driven by Takt time. A level loaded schedule can be obtained as follows: $\mathrm{N}$ daily work time daily quantity needed Calculate $=$ Take time. For each part, list part name, part number, daily quantity needed, Takt time. Sort the list by quantity needed and Takt time. This is the level loaded schedule [14].

The Pull systems are opposite to the traditional mass production push system. The Push systems can be summarized as "Make a lot of stuff as cheaply as possible and hope people will buy it." Push systems minimize the number of setups and changeovers and use dedicated, specially designed equipment to produce identical units. The pull systems can be summarized as "Do not make anything until it is needed, then make it fast”. The pull system controls the flow and quantity produced by replacing items when they are consumed. The storage area of a modern super- market is very small compared to the retail floor area. In fact, supermarkets were the inspiration behind Taiichi Ohno's creating Lean at Toyota. The pull systems require level loading and flexible processes Flexible process [15].

Flexible processes are lightweight and manoeuvrable tools, and fixtures and equipment located and positioned to improve safety, ergonomics, quality, and productivity. They are the opposite of the big, heavy, permanently positioned counterparts traditionally used for mass production. A flexible shop can be quickly reconfigured to produce different items to meet changing customer demands. Flexible processes are related to level loading and pull. A completely flexible process would be reconfigured to produce an item as soon as an order for it arrived. This ideal cannot be met, but it can be approximated over some small-time interval, such as the factory is able to change the lot size in short time.

Lot size refers to amount of an item that is ordered from the plant or supplier or issued as a standard quantity to the production process. The ideal lot size for flow is one. Larger lot sizes lead to larger quality problems due to delayed feedback, excessive inventory, obsolete inventory, etc. Of course, there are offsetting benefits such as quantity discounts, fewer setups, lower transportation costs, etc. In practice, the costs and benefits must be balanced to achieve an optimum.

\section{Development of cost optimization in a supply chain}

Production scheduling allocates available capacity (equipment, labor and facilities) to the work that needs to be done. The goal is to use available capacity in the most efficient and profitable manner [16]. The productionscheduling operation is a process of finding the right balance between several competing objectives: High utilization rates- this often means long production runs and centralized manufacturing and distribution centers [17]. The idea is to generate and benefit from economies of scale, - this usually means short production runs and just-intime delivery of raw materials. The idea is to minimize the assets and cash tied up in inventory High levels of customer service- this often requires high levels of inventory or many short production runs. The aim is to provide the customer with quick delivery of products and not to run out of stock 
Table 1 Variable costs

\begin{tabular}{lccc}
\hline variable costs & $\begin{array}{c}\text { fixed producing } \\
\text { capacity }\end{array}$ & $\begin{array}{c}\text { retail lean management } \\
\text { approach }\end{array}$ & $\begin{array}{c}\text { fixed production capacity with } \\
\text { EOQ approach }\end{array}$ \\
\hline production set up costs & 0.00 & 3.20 & 0.00 \\
transportation and ordering costs & 38.40 & 38.40 & 34.40 \\
holding costs & 50.00 & 39.00 & 20.00 \\
total costs & 88.40 & 80.60 & 54.40 \\
\hline
\end{tabular}

of any product. The base model (Appendix 1), developed for supply chain variable cost optimization, is built on these assumptions:

- The basic data show products placed on an expected sales of retailer and the fixed volume purchase plan,

- Producer plans fixed volume production schedule considering the expected customer needs for the period,

- Distributor purchases end sells goods in terms of producer and retailer inventory plans.

- Considering the high-level service performance retailer and distributor keep minimum lunit safety stock, which influences the stock opening balances.

- The ordering stock USD 1 and USD 0.8 for retailer (per order), the retailer does not transport the goods towards.

- The transportation cost per delivery USD 0.4 for producer and USD 0.2 for distributor assuming lunit truck capacity for producer and 0.8 for distributor.

- The carrying (holding) stock USD 2 and USD 1 for retailer and distributor respectively (per stock value).

The runout time calculation for a product is expressed as $\mathrm{R}=\mathrm{P} / \mathrm{D}$ where: $\mathrm{R}=$ runout time on hand $\mathrm{P}=$ number of units of product Dproduct demand in units for a day or week, in this case the planed customer demand 24 unit for 6 periods, so the producing lot size in a period 4units. Taking into account the basic assumptions of the basic model (Appendix 1) with fixed production, the total variable cost in the supply chain USD 88.4 of which the retailer bears USD 48.8 (Table 1). When a single product is to be made in a dedicated facility, scheduling means organizing operations as efficiently as possible and running the facility at the level required to meet demand for the product.

The second step in scheduling the purchase, when retailer would like to decrease the average inventory level using the lean approach expecting the decrease of total logistic variable cost (Appendix 2). The task is to determine the economic lot size for the production runs of each product. If production costs are minimized by doing long production runs, then inventory levels will be higher and product inventory carrying costs will be higher. Once production quantities have been determined, the second step is to set the right sequence of production runs for each product. The basic rule is that if inventory for a certain product is low relative to its expected demand, then production of this product should be scheduled ahead of other products that have higher levels of inventory relative to their expected demand. The main difference from the fixed production schedule is the set-up cost for manufacturer because of the need of flexible capacity. In the model it is assumed USD 0.8 if production volumes change between the two periods, calculating with the same ordering and carrying costs which are used for basic model, thetotal variable cost in the supply chain USD 80.6 of which the retailer bears USD 16.8. Notice the decreased total cost in spite of the increased cost level for the whole supply chain and the retailer does not carry the goods toward. The retailer could decrease its average inventory at the expense of distributor and besides the producer bears the fluctuating production schedule.

The third step in scheduling a single production facility is to determine the economic lot size for the production runs of each product with less ordering transaction and avoiding the cost due to the cost of production capacity change. This is a calculation much like the economic order quantity (EOQ) calculation used in the inventory control process. The calculation of economic lot size involves balancing the production setup costs for a product with the cost of carrying that product in inventory. If setups are not done and production runs are done in bigger batches, the result will be higher levels of inventory, but the production costs will be lower due to eliminated or decreased setup activity (Appendix 3). Finally, the integrated supply change management could push down the total costs below the original level using the fixed production schedule and more flexible purchase plan, the total cost: USD54.4. Notice the distributor purchase the goods in term of fixed production schedule and flexible retailer buying strategy focusing on economic order quantities. The retailer focuses on the minimum closing stock which enough to keep the safety level.

Inventory aggregation decisions must account for inventory and transportation costs. Inventory aggregation decreases the supply chain costs if the product ordered in terms of economic quantity, resulting low transportation costs, and customer orders are large. If a product was produced with fixed capacity, low demand uncertainty, large transportation cost, or small customer orders, inventory aggregation may increase supply chain costs. If a product was produced in a flexible way, high demand uncertainty, large transportation costs, or small customer orders, inventory aggregation may increase supply chain costs, including the production set up cost. 
Table 2 Summary of supply chain cost

\begin{tabular}{|c|c|c|c|}
\hline variable costs & $\begin{array}{l}\text { fixed producing } \\
\text { capacity }\end{array}$ & $\begin{array}{l}\text { retail lean management } \\
\text { approach }\end{array}$ & $\begin{array}{l}\text { fixed production capacity with } \\
\text { EOQ approach }\end{array}$ \\
\hline production set up costs & 0.00 & 3.20 & 0.00 \\
\hline transportation and ordering costs & 38.40 & 38.40 & 34.40 \\
\hline holding costs & 5.00 & 3.90 & 2.00 \\
\hline total costs & 43.40 & 45.50 & 36.40 \\
\hline
\end{tabular}

\section{Conclusion}

Order management is the process of passing order information from customers back through the supply chain from retailers to distributors to service providers and producers. This process also includes passing information about order delivery dates, product substitutions and back orders forward through the supply chain to customers. In the examined model this process has long relied on used information such as purchase orders, sales orders, change orders. Retailer company generates a purchase order and calls a supplier to fill the order. The delivery scheduling operation is of course strongly affected by the decision made concerning the modes of transportation that will be solved and the delivery-scheduling process works within the constraints set by transportation decisions. For the verified method the direct deliveries are assumed. Direct deliveries are made from one originating location to one receiving location. With this method of delivery, the routing is simply a matter of selecting the shortest path between the two locations Scheduling this type of delivery involves decisions about the quantity to deliver and the frequency of deliveries to each location. The advantages of this delivery method are found in the simplicity of operations and delivery coordination. With respect to suppliers, retailers, buyers have to negotiate continually lower prices. Due to its volume power, buyer can often force the integration of suppliers' operations into its supply chain. This might imply the implementation of a joint business plan with contracts specifying price, volume, delivery schedule, packaging and quality. It might also involve a subsequent close monitoring of their suppliers' production and gaining access to their books and accounts. In this paper an integrated model is demonstrated, where the popular lean approach is developed towards an Economic Lean Method on supply chain level. It is not enough to optimize the inventory level through less stocking, more important to optimize the cost on supply chain level in spite of the higher asset requirements. The one-sided lean approach does not take into account external costs either because of increase or more frequent product movement. The stock itself is not an enemy, the real friend of business the asset efficiency.

As the costs presented in Table 2, the transportation and ordering costs are higher than the economic order of quantity is the primary determinant in supply chain management. Although the lean approach helps to reduce the inventory level, at the same time in retail sector the intensive volume of movement of goods increase the transportation and ordering costs not to mention the external costs, but this last issue could be a topic of a new research.

\section{Acknowledgements}

This publication was realized with support of Operational Program Integrated Infrastructure 2014 2020 of the project: Innovative Solutions for Propulsion, Power and Safety Components of Transport Vehicles, code ITMS 313011V334, co-financed by the European Regional Development Fund.

\section{References}

[1] CHOPRA, S., MEINDL, P. Supply chain management.6. ed. Pearson, 2016. ISBN 978-013-38-00-57-9.

[2] GOLDRATT, E. M. The goal: a process of ongoing improvement. 30. ann. ed. Great Barrington, MA: North River Press, 2014. ISBN 978-088-42-71-95-6.

[3] HUGOS, M. Essentials of supply chain management. Wiley, 2018. ISBN 978-1-119-46110-4.

[4] ZENTES, J., MORSCHETT, D., SCHRAMM-KLEIN, H. Retail branding and positioning [online]. In: Strategic retail management. Gabler Verlag, 2011. ISBN 978-3-8349-2536-7, eISBN978-3-8349-6740-4, p. 179-200. Available from: https:// doi.org/10.1007/978-3-8349-6740-4_10

[5] COYLE, J. J., BARDI, E. J., LANGLEY, C. J. The management of business logistic: a supply chain perspective. 7 . ed. Mason: South-Western College Pub., 2003. ISBN 978-0324007510.

[6] BERMAN, B. R., EVANS, J. R. Retail management: a strategic approach. 10. ed. Pearson, 2007. ISBN 978-013-18-70-16-1.

[7] LEVY, M., WEITZ. B. A. Retailing management. 9. ed. McGraw-Hill Education, 2013. ISBN 978-007-80-28-99-1.

[8] GILBERT, D. Retail marketing management. 4. ed. Financial Times Prentice Hall, 2003. ISBN 978-027-36-55-11-4. 
[9] ZENTES, J., MORSCHETT, D., SCHRAMM-KLEIN, H. Strategic retail management [online]. 3. ed. Gabler, 2017. ISBN 978-3-658-10182-4, eISBN978-3-658-10183-1. Available from:https://doi.org/10.1007/978-3-658-10183-1

[10] CHOPRA, S., DOUGAN, D., TAYLOR, G. B2B e-commerce opportunities. Supply Chain Management Review. 2001, 5(3), p. 50-58. ISSN 1521-9747.

[11] VOKURKA, R., LUMMUS, R. The role of just in time in supply chain management. The International Journal of Logistics Management [online]. 2000, 11(1), p. 89-98. ISSN 0957-4093. Available from: https://doi.org/10.1108/09574090010806092

[12] AGARDI, I. Kereskedelmi marketing es menedzsment / Commercial marketing and management (in Hungarian). Budapest: Akademiai Publishing, 2010. ISBN 978-963-05-89-40-6.

[13] VAN DER VORST, J. G. A. J., VAN DIJK, S. J., BEULENSA. J. M. Supply chain design in the food industry. The International Journal of Logistics Management [online]. 2001, 12(2), p 75-75 [accessed 2015-08-05]. ISSN 0957-4093. Available from: https://doi.org/10.1108/09574090110806307

[14] CHRISTOPHER, M., TOWILL, D. R. Developing market specific supply chain strategies. International Journal of Logistics Management [online]. 2002, 13(1), p 10-11. ISSN 0957-4093. Available from: https://doi.org/10.1108/09574090210806324

[15] SMITH, D., SPARKS, L. Logistics in Tesco: past, present and future. In: Logistics and retail management. FERNIE, J.; SPARKS, L. (eds.). 2. ed. London, UK: London and Sterling, VA, 2004. ISBN 0-7494-4091-0, p. 101-120.

[16] EVANS, W. S., BLAWATT, S. The growth potential in managing supplier risk. Supply Chain Management Review. 2010, 14(4), p. 30-35. ISSN 1521-9747.

[17] FEDORKO, G., MOLNAR, V., DOVICA, M., TOTH, T. Conveyor belt quality assessment for in-house logistics. Quality Access to Success. 2018, 19(166), p. 35-38. ISSN 1582-2559.

\section{Appendix 1 Fixed producing schedule}

\begin{tabular}{lcccccc}
\hline Retail & Period 1 & Period 2 & Period 3 & Period 4 & Period 5 & Period 6 \\
\hline opening stock & 5.0 & 6.0 & 5.0 & 2.0 & 1.0 & 3.0 \\
purchase & 4.0 & 4.0 & 4.0 & 4.0 & 4.0 & 4.0 \\
sales & 3.0 & 5.0 & 7.0 & 5.0 & 2.0 & 2.0 \\
closing stock & 6.0 & 5.0 & 2.0 & 1.0 & 3.0 & 5.0 \\
\hline
\end{tabular}

\begin{tabular}{lcccccc}
\hline Distributor & Period 1 & Period 2 & Period 3 & Period 4 & Period 5 & Period 6 \\
\hline opening stock & 1.0 & 1.0 & 1.0 & 1.0 & 1.0 & 1.0 \\
purchase & 4.0 & 4.0 & 4.0 & 4.0 & 4.0 & 4.0 \\
sales & 4.0 & 4.0 & 4.0 & 4.0 & 4.0 & 4.0 \\
closing stock & 1.0 & 1.0 & 1.0 & 1.0 & 1.0 & 1.0 \\
\hline
\end{tabular}

\begin{tabular}{lcccccc}
\hline Producer & Period 1 & Period 2 & Period 3 & Period 4 & Period 5 & Period 6 \\
\hline manufacturing & 4.0 & 4.0 & 4.0 & 4.0 & 4.0 & 4.0 \\
cumulated selling & 4.0 & 8.0 & 12.0 & 16.0 & 20.0 & 24.0 \\
\hline
\end{tabular}

Source: The authors' own edition

Appendix 2 Flexible producing schedule with retailer lean approach

\begin{tabular}{|c|c|c|c|c|c|c|}
\hline Retail & Period 1 & Period 2 & Period 3 & Period 4 & Period 5 & Period 6 \\
\hline opening stock & 1.0 & 1.0 & 1.0 & 1.0 & 1.0 & 1.0 \\
\hline purchase & 3.0 & 5.0 & 7.0 & 5.0 & 2.0 & 2.0 \\
\hline sales & 3.0 & 5.0 & 7.0 & 5.0 & 2.0 & 2.0 \\
\hline closing stock & 1.0 & 1.0 & 1.0 & 1.0 & 1.0 & 1.0 \\
\hline
\end{tabular}




\begin{tabular}{lcccccc}
\hline Distributor & Period 1 & Period 2 & Period 3 & Period 4 & Period 5 & Period 6 \\
\hline opening stock & 1.0 & 1.0 & 1.0 & 8.0 & 8.0 & 8.0 \\
purchase & 3.0 & 5.0 & 7.0 & 5.0 & 2.0 & 2.0 \\
sales & 3.0 & 5.0 & 7.0 & 5.0 & 2.0 & 2.0 \\
closing stock & 1.0 & 1.0 & 1.0 & 8.0 & 8.0 & 8.0 \\
\hline
\end{tabular}

\begin{tabular}{lcccccc}
\hline Producer & Period 1 & Period 2 & Period 3 & Period 4 & Period 5 & Period 6 \\
\hline fix capacity & & & & & & \\
manufacturing & 3.0 & 5.0 & 7.0 & 5.0 & 2.0 & 2.0 \\
cumulated selling & 3.0 & 8.0 & 15.0 & 20.0 & 22.0 & 24.0 \\
\hline Source: The authors' own edition & & & &
\end{tabular}

Source: The authors' own edition

\section{Appendix 3 Fixed production capacity with EOQ approach}

\begin{tabular}{|c|c|c|c|c|c|c|}
\hline Retail & Period 1 & Period 2 & Period 3 & Period 4 & Period 5 & Period 6 \\
\hline opening stock & 4.0 & 1.0 & 1.0 & 1.0 & 1.0 & 1.0 \\
\hline purchase & & 5.0 & 7.0 & 5.0 & 2.0 & 2.0 \\
\hline sales & 3.0 & 5.0 & 7.0 & 5.0 & 2.0 & 2.0 \\
\hline closing stock & 1.0 & 1.0 & 1.0 & 1.0 & 1.0 & 1.0 \\
\hline
\end{tabular}

\begin{tabular}{|c|c|c|c|c|c|c|}
\hline Distributor & Period 1 & Period 2 & Period 3 & Period 4 & Period 5 & Period 6 \\
\hline opening stock & 2.0 & 6.0 & 5.0 & 2.0 & 1.0 & 3.0 \\
\hline purchase & 4.0 & 4.0 & 4.0 & 4.0 & 4.0 & 4.0 \\
\hline sales & & 5.0 & 7.0 & 5.0 & 2.0 & 2.0 \\
\hline closing stock & 6.0 & 5.0 & 2.0 & 1.0 & 3.0 & 5.0 \\
\hline Producer & Period 1 & Period 2 & Period 3 & Period 4 & Period 5 & Period 6 \\
\hline \multicolumn{7}{|l|}{ fix capacity } \\
\hline manufacturing & 4.0 & 4.0 & 4.0 & 4.0 & 4.0 & 4.0 \\
\hline cumulated selling & 4.0 & 8.0 & 12.0 & 16.0 & 20.0 & 24.0 \\
\hline
\end{tabular}

